\title{
Application of the ALE FE method to debris flows
}

\author{
I. Konuk ${ }^{1}, \mathrm{~S} . \mathrm{Yu}^{1} \&$ E. Evgin ${ }^{2}$ \\ ${ }^{1}$ Geological Survey of Canada, Ottawa, Ontario Canada \\ ${ }^{2}$ University of Ottawa, Ottawa, Ontario, Canada
}

\begin{abstract}
A computational model illustrating the application of the ALE FE method to simulate three dimensional debris flows is presented. The paper studies the influence of the initial and boundary conditions on the dynamics of the debris flows on simplified terrain geometry. The effects of the loading conditions and soil properties are also illustrated. The paper demonstrates the applicability and versatility of the ALE method for the debris flow problem while satisfying all the principles of continuum mechanics.
\end{abstract}

Keywords: debris flow, finite element, ALE, computational geomechanics.

\section{Introduction}

Debris flows are fast moving landslides. They can happen on land or on submarine slopes. They may consist of a mixture of soils, fragments of rock, and water. Debris flows can also travel several miles from their source. As they move, they can grow in size as they may pick up additional material or may trigger larger flows. Large submarine flows were reported off the east coast of Canada and west coast of Norway. One extensively studied submarine slide in Norway involved about $6000 \mathrm{~km}^{3}$ of soil [1]. Engineers face the task of predicting the volume, velocity of the debris flows as well as the distances they may travel and the magnitudes of forces that they would exert on structures located on their path.

The debris flows may be initiated by various forms of instabilities on sloping ground caused by heavy rainfall, rapid snowmelt, earthquake shaking, sediment accumulation, or volcanic eruptions. Limit equilibrium, finite element (FE), and finite difference methods are used to determine the conditions that may initiate a 
slope failure or landslide. Most of these methods are limited to the prediction of the limiting conditions before a slide can be initiated. Some of the numerical methods can follow the slide process beyond unstable equilibrium, but usually to relatively short distances from the equilibrium conditions.

The mechanics of debris flows have been studied extensively in literature. Many solutions have been proposed using experimental, empirical, and numerical methods. Numerous workshop proceedings illustrate the popularity of the subject $[2,3,4]$. The objective of this paper is to show that the debris flow problem can be solved by applying the Arbitrary Lagrangian Eulerian (ALE) Finite Element (FE) numerical method to a continuum mechanics based formulation of the problem, avoiding the limitations of some of the other numerical methods.

In this paper, the mechanics of the initiation of the debris flows will not be addressed. In the models studied, the debris flows are initiated either by creating an instability by removing a confining structure or by applying an inertial acceleration simulating the effect of an earthquake. Two forms of idealized boundary conditions will be applied to distinguish the flow processes that start in the form of a deformation from those that start due to the complete detachment of a certain soil mass. It is assumed that the mass of the debris flow remains constant and no additional instabilities are triggered during the progress of the debris flow. The debris mass involved will be assumed to be constituted from a single phase material which can be characterized by a continuum constitutive model which will be called soil throughout the rest of the paper.

A detailed description of the debris flow mechanics will be presented in the next section. A brief review of the numerical methods developed to solve the debris flow problem in literature will also be presented in Section 2. In Section 3, a detailed description of the ALE FE model will be provided. Section 4 presents the results obtained from various models with different loadings or excitations and different boundary conditions. In section 5, extension or generalization of the models developed in this paper will be discussed. Some brief conclusions will also be presented.

\section{Description of the problem and review of numerical and constitutive models}

The debris flow problem in general requires the solution of a set of partial differential equations including conservation of mass and conservation of momentum, while satisfying material constitutive relationships involving stress and strain and their time derivatives. The debris flow problem presents a special challenge compared to other computational mechanics problems as it requires the solution of a moving boundary problem spread across a very large domain subject to complex contact or interface conditions. High speeds require accurate consideration of the inertia effects. In addition, the constitutive model has to remain valid across very complex stress paths while satisfying the laws of thermodynamics [5]. In some cases, the debris flow materials may have to be treated as multiphase. 


\subsection{Computational methods}

Various computational techniques have been used in the last decade to solve soil mechanics problems. Reference [6] illustrates the application of a commercial software tool (FLAC) to solve a slope stability problem and to predict the resulting soil movements. The numerical method used there is based on the finite difference method. As can be seen from this reference, the method is limited to deformations of a few meters.

There is a large number of publications on debris flows that utilizes an equation of state, called Bingham fluid $[7,8]$. The approach relies on techniques derived from computational fluid mechanics. In this approach, hardening or softening effects, dilation or contraction, and energy dissipation through plastic flow are neglected.

Specialized numerical techniques have been developed by Pastor and coworkers to overcome this difficulty [9, 10]. They implemented their numerical solution techniques in specialized software. They have adopted an approach from hydrology where the through-thickness stress and strain field is represented by equivalent values mapped to the surface of the terrain in order to reduce the problem to two dimensions. This is analogous to the Fourier FE method [11]. Special care has to be taken to apply this method if the aim is to predict the distance of travel or to calculate the forces on structures that the debris flow encounters. Another two dimensional approach which reduces the problem to the elevation plane by Crosta et al. [12] utilizes the more generalized ALE method.

A promising technique developed in the last few years is Smoothed Particle Hydrodynamics (SPH). A special case of this technique has been applied to debris flow problem by McDougall and Hungr [13]. Although this approach is based in principle on a rigorous theory, it is very hard to apply to complex domains with strong discontinuities, and it is difficult to integrate complex constitutive models with the SPH method. In fact, in this reference, a simple Mohr-Coulomb type material is utilized. In addition, the depth averaging is used to reduce the problem to a two dimensional one.

Another technique used is the Discrete Element Method (DEM). Crosta et al. [14] uses DEM method to solve a two dimensional debris flows problem. Although this method is presented as a numerical method, it is actually not based on discretization of the equations of continuum mechanics. It is mainly based on an analogy that is used to derive the particle (interaction) parameters from some laboratory tests. Not only is it difficult to simulate complex stress paths, but also one can not handle constitutive behaviour with dilatancy or contraction. The DEM method may be more applicable for blocky rock flows where the continuum approximation may break down [15].

The FE discretization of the continuum mechanics equations is well developed for the Lagrangian formulation [16]. However, the applicability of the Lagrangian formulation to the debris flow is very limited due to extreme mesh distortion resulting from the very large deformation of the solution domain. Updated Lagrangian methods can be used to overcome this difficulty when the material constitutive model is relatively simple. ALE formulation has been 
developed in the last decade to handle fluid-structure interaction problems where one encounters large distortion of the solution domain, muti-material interactions, and complex material constitutive models. Recently, Konuk et al. [17] applied this method to solve a complex soil-structure interaction problem; ice scour of seabed. In fact, there are strong similarities between ice scour and debris flows. In ice scour, the structure (ice) is in motion whereas in debris flows, the soil (debris) is in motion. However, in both cases, soil mass is moved large distances.

In the ALE method, the analysis undergoes three major steps. In the first step, a standard Lagrangian FE analysis is conducted. In the second step, the FE mesh is remapped based on some smoothing criteria. The remapping algorithms can be based on the stresses and the deformations obtained in the previous time step or on the mesh topology. The third step in the ALE approach is the advection phase. In this step the discretized strain, mass, and momentum parameters are computed for the nodes of the new mesh. In reference [18], Souli describes the algorithms used to accomplish the last step in the LS-DYNA software [19] which is used to obtain the results presented in this paper.

\subsection{Selection of constitutive model}

Prevost and Popescu [20] presented an extensive review of soil constitutive models from the view point of their applicability in computational modelling. As indicated by Prevost and Popescu, the most popular and widely used soil models in computational geomechanics are CAP models [21 and 22] based on classical isotropic plasticity theory. Although the original CAP models have some limitations - they do not adequately model stress-induced anisotropy and they are not applicable to cyclic loading conditions - these issues do not pose a serious shortcoming in the modelling of debris flow problem. The other attractive feature of the CAP model is that it is easy to derive the CAP constitutive model parameters by applying relatively simple laboratory tests. Sandler et al. [23] extended the CAP model to include pore pressure effects and kinematic hardening in their prediction of the behaviour of anisotropic wet clay. The soil was assumed to be fully saturated and incompressible under undrained test conditions.

Therefore, it was decided to use the CAP model implemented in LS-DYNA software [19]. The LS-DYNA CAP model was originally developed by Sandler [21] and was later modified by Simo et al. [24]. Debris flow soil parameters were selected similar to the ice scour soil model parameters [17].

\section{Finite element model}

Finite element discretization is done using LS-DYNA (Version 970) Explicit FE software [18]. The model includes a soil placed in a trapezoidal prism box placed on the side of a slope represented by a rigid shell structure. The soil is kept in place by a rigid wall placed in front until gravity loading attains a steady state condition. Several different models were developed with different slope 
geometries and different boundary conditions. The finite element mesh used for implementing the model is shown in fig. 1.

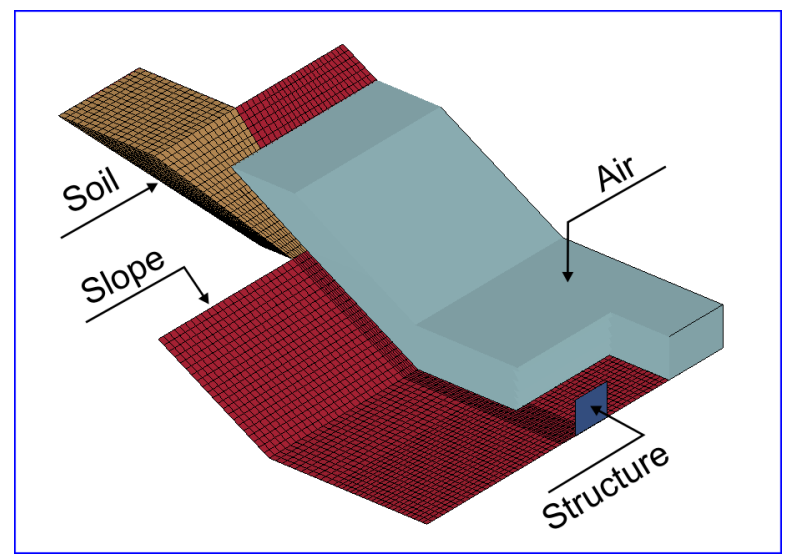

Figure 1: Finite element model.

The developed models consist of soil, air and the slope. Soil is modelled using 8 node constant stress (one point integration) solid elements. In LSDYNA, the void elements were used to represent the air which can accept material from other neighbouring elements. The slope is modelled using rigid shell elements. The dimensions of the soil tank are $15 \mathrm{~m} \times 15 \mathrm{~m}$ at the top and $5 \mathrm{~m} \times 5 \mathrm{~m}$ at the bottom. The length as measured along the slope is taken to be $20 \mathrm{~m}$. The total length of the slope is $40 \mathrm{~m}$. The depth of the void layer is chosen to accommodate the debris flow mass at all times. A small rigid structure is placed in front of the model to illustrate the effects of such a structure on the pattern of the debris flow and to calculate the loads imposed on such a structure. Soil parameters for all cases presented in this paper are given in the Appendix.

The soil and void elements are defined as Eulerian elements. Thus, the soil and void element nodes are fixed. Soil mass is allowed to move through both the soil and the void meshes. The friction factor is taken to be 0.0 between the soil and the rigid shell representing the slope. This assumption is partially justified by the hydroplaning phenomena in submarine slides [1] and also because increased shear strains near the boundary would reduce the effective friction angle of the dilative soil at the interface. The mesh density is taken to be finer near the areas where large soil strains and displacements are expected. Limited mesh objectivity studies were conducted before adopting the final FE mesh.

Two sets of boundary conditions were imposed. In one case, which is called the fixed boundary case, all degrees of freedom for the nodes at the bottom and sides of the soil box were fixed. This case was designed to idealize a deformation based failure initiation. In the second case, the normal degrees of freedoms were constrained while allowing tangential movements. This case was developed to simulate a slip surface type failure. 


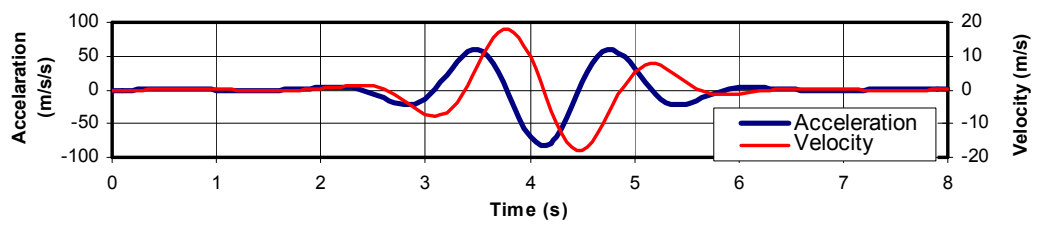

Figure 2: Earthquake accelerations and velocities.

Since the model is an explicit dynamic FE model, special attention is required when applying the external and body loads. Soil mass is taken to be stress free and to have uniform properties in the initial state. The loads are imposed in three steps. In the first step, gravitational acceleration is applied. Sufficient time is allowed to ensure that the soil stresses reach a stationary state. This step ensures that the stress state in the seabed soil is representative of natural conditions and is mechanically admissible with the soil constitutive model used in the analysis. In the second step, the barrier holding the soil in its box is removed. For seismic loading cases, a third load step is applied. The model, in these cases, is accelerated in the horizontal $(\mathrm{X})$ direction by a function given in fig. 2 . The velocity function given in fig. 2 is an approximation of the earthquake velocities provided by Daddazio et al. [25].

The LS-DYNA program outputs material density and mass quantity in partially filled elements, the soil stresses and strains, the velocity field in the flow and the forces exerted by the flow on other bodies that it contacts. In addition, "Tracer Particles" can be imbedded in various parts of the soil mass to store the calculated parameters. These particles do not affect the solution but allow the user to store various calculated parameters such as stresses and strains along with the position of the particles as the soil mass moves across the Eulerian mesh.

\section{Discussion of results}

Fig. 3 presents output from a fixed boundary case at different time steps after the barrier is removed from the front of the soil box. In that figure, part of the slope is removed in order to expose the soil strains in the mid-plane. In fig. 3, soil streamlines created by the Tracer Particles as well as the effect of the structure in the front are illustrated.

Fig. 4 illustrates the importance of the boundary conditions at the initiation of the flow. As it can be seen from this figure, the flows that start with catastrophic slip surface slope failures will accelerate quicker and will dispose more soil mass than surficial flows.

Fig. 5 presents the soil densities at 10 seconds after the initiation of the debris flow for soils with different CAP parameter $\theta$ values; with $0.130,0.140,0.142$, and 0.144 corresponding to soil internal friction angle from about 10 degrees to 20 degrees. Fig. 5 shows the importance of the soil properties. This figure 
illustrates that the flow type failures do not initiate at a unique threshold value of $\theta$ (or the friction angle). Rather flow size grows as the soil gets weaker. The other importance of this figure is that it shows the adaptability of the ALE method to complex free boundary value problems.

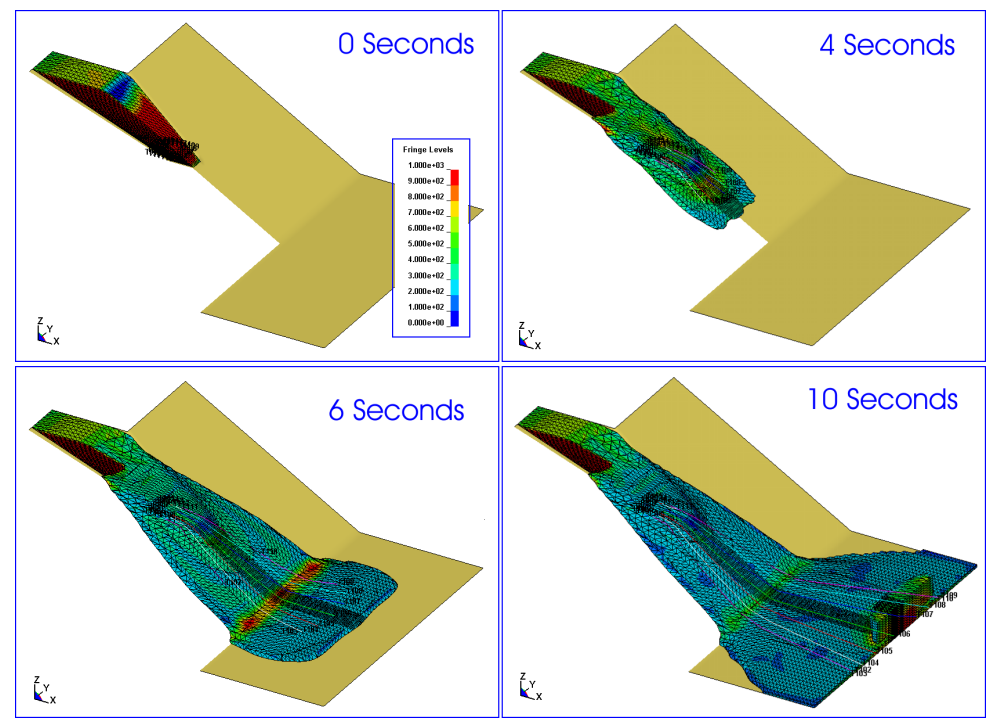

Figure 3: Plastic strains (Case\#1107 - 30 Degree Slope - Fixed boundary).
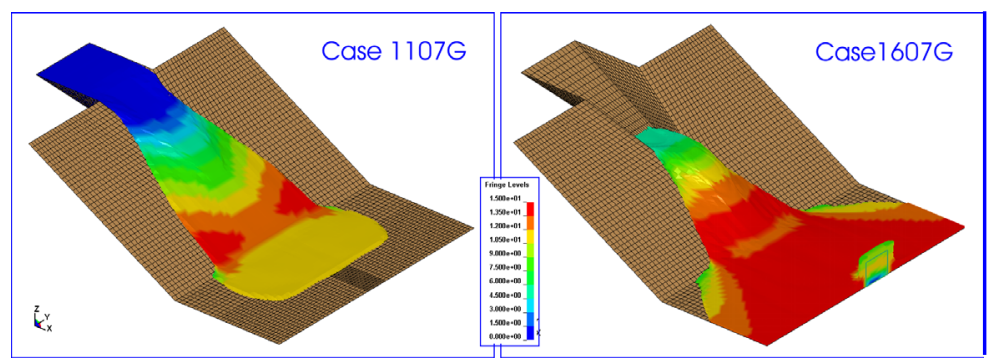

Figure 4: Velocities at $6 \mathrm{~s}$ for fixed and free boundary conditions

Fig. 6 illustrates the velocity fields for debris flows initiated by earthquake loadings similar to the one used by Daddazio et al. [25] for a $\theta$ value of 0.144 . Frames in fig. 6 correspond to different amplification factors which are multiplied by the acceleration function shown in fig. 2. Fig. 6 illustrates the influence of the earthquake energy on the magnitude and speed of the debris flow. The first frame in this figure shows that this slope would normally be stable if there were no earthquake excitation.

As it can be seen from the figures 3 to 6 , the method can simulate most aspects of the debris flows including the free surface effects such as the surface waves or ripples generated during the flow. 
54 Monitoring, Simulation, Prevention and Remediation of Dense and Debris Flows

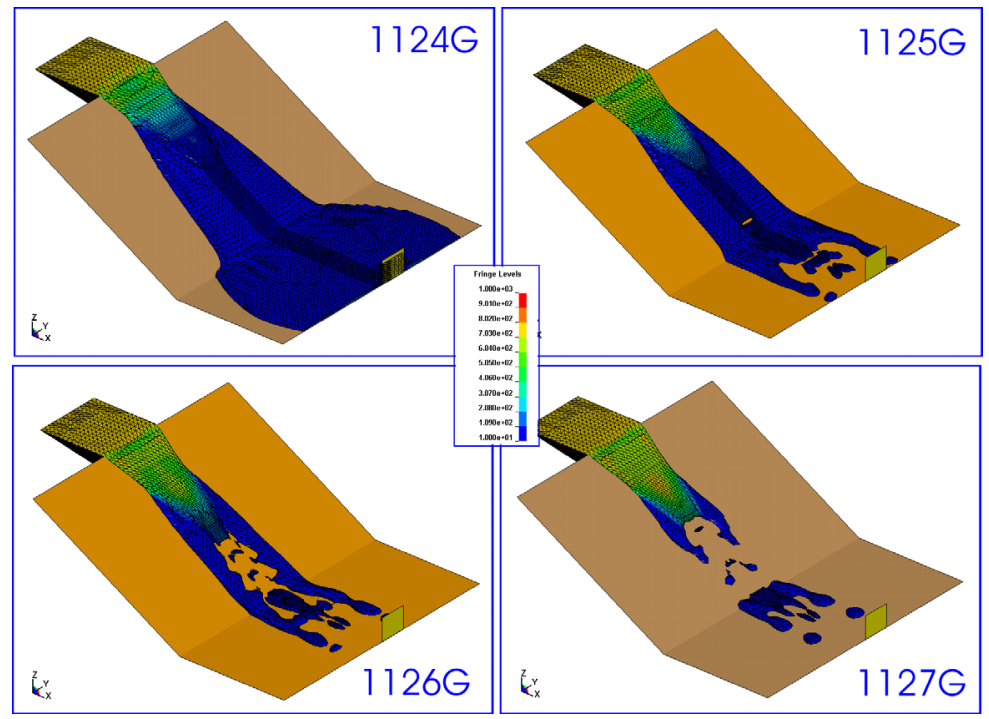

Figure 5: Soil densities at $10 \mathrm{~s}$ for different soil properties (30 Degree Slope Fixed boundary).

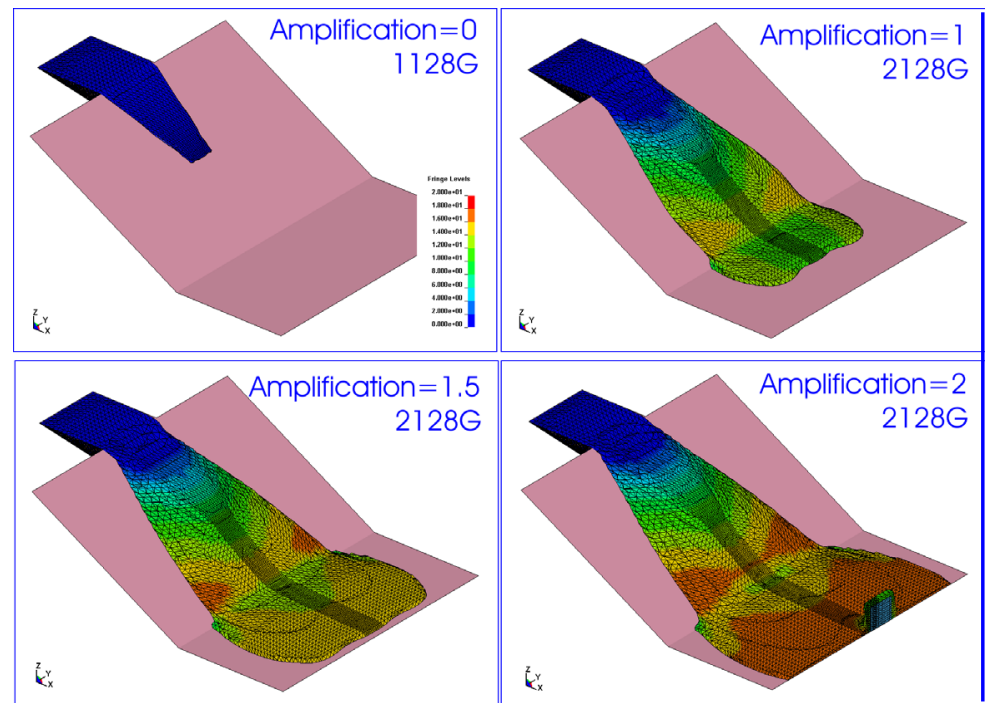

Figure 6: Soil velocities for earthquake loadings after 6 Seconds (30 Degree slope - Fixed boundary).

Fig. 7 presents the stress paths located at two levels, one closer to the slope surface and one closer to the failure surface. This figure illustrates that the CAP constitutive model can accommodate stress paths encountered during the debris 
flows. It can also be seen that deeper particles experience more complex stress paths; spending more time on the CAP surface than particles closer to the surface. These particles later go through a stress rotation as the CAP shrinks for a small distance.



Figure 7: Soil stress paths from tracer particles.

\section{Conclusions}

It has been shown that ALE method in conjunction with the CAP constitutive model can be used to solve the debris flow problem as stated in the beginning of this paper. This approach overcomes the simplifications and approximations required by other numerical methods. It can accurately calculate all aspects of the dynamics of the debris flow. It can calculate the surface effects. It calculates velocities and accelerations accurately in three dimensions. Since it uses a realistic soil constitutive model, it can determine the dissipated energy through plastic flow inside the soil mass. This method can therefore calculate the travel distances and forces generated by a debris flow very accurately.

Although the model geometry presented in this paper is fairly simple, there is no obstacle to apply this approach to more realistic terrains with complex geometries, different textures (contact conditions), and different initiation conditions.

\section{References}

[1] De Blasio, F.V., Elverhøi, A., Issler, D., Harbitz, C.B., Bryn, P. \& Lien, On the dynamics of subaqueous clay rich gravity mass flow - the giant Storegga slide, Norway, Marine and Petroleum Geology, 22, 179-186, 2005.

[2] Jacob, M. \& Hungr, O. (eds), Debris-flow Hazards and Related Phenomena, (739 p). Springer-Praxis Publishing, Chichester, UK, 2005. 
[3] Rickenmann, D. \& Chen, C-L. (eds), Debris-flow Hazards Mitigation: Mechanics, Prediction, and Assessment (1335 p), Millpress, Rotterdam, 2003.

[4] Wieczorek, G.F. \& Naeser, N.D. (eds), Debris-flow Hazards Mitigation: Mechanics, Prediction, and Assessment (608 p). A.A. Balkema, Rotterdam, 2000.

[5] Collins, I.F., \& Kelly, P.A., A thermomechanical analysis of a family of soil models, Geotechnique 52, No. 7, 507-518, 2002.

[6] Benko B. \& Stead D., The Frank slide: a reexamination of the failure mechanism. Can. Geotech. J., 35(2), pp. 299-311, 1998.

[7] Sousa, J. \& Voight, B., Continuum simulation of flow failures, Geotechnique, 41(4), pp. 515-538, 1991.

[8] Iverson, R.M., The physics of debris flows. Reviews of Geophysics, 35, pp. 245-296, 1997.

[9] Pastor, M., Quecedo, M., Fernandez Merodo, J.A., Herrores, M.I., Gonzalez, E., \& Mira, P., Modelling tailings dams and mine waste dumps failures. Geotechnique, 52(8), pp. 579-591, 2002

[10] Quecedo, M. \& Pastor, M., Application of level set method to the finite element solution of two-phase flows. Int. J. Numer. Methods Engng. 50, pp. 645-663, 2001.

[11] Belhachmi Z., Bernardi C., Deparis S., \& Hecht F., A truncated Fourier/finite element discretization of the Stokes equations in an axisymmetric domain, Mathematical Models and Methods in Applied Sciences (M3AS) 16, 2, 233-263, 2006.

[12] Crosta, G.B., Imposimato, S., Roddeman, D.G., Chiesa, S. \& Moia, F. Small fast moving flow-like landslides in volcanic deposits: the 2001 Las Colinas Landslide (El Salvador), Engineering Geology, 79, 185-214, 2005

[13] McDougall, S. \& Hungr, O., A model for the analysis of rapid landslide motion across three-dimensional terrain, Canadian Geotechnical Journal, 41(6), pp. 1084-1097, 2004

[14] Crosta, G., Calvetti, F., Imposimato S., Roddeman D., Frattini P., \& Agliardi F., Granular Flow and Numerical Modelling of Landslides, DAMOCLES report, 2001.

[15] Cundall, P.A., A Computer Model for Simulating Progressive Large Scale Movements of Blocky Rock Systems, Proceedings, ASCE, Symp. Int. Soc. Rock. Mech., Nancy, France, Vol. 1, pp. 132-150, 1971.

[16] Belytschko, T., Liu, W.K., \& Moran, B., Nonlinear Finite Elements for Continua and Structures, Wiley, New York (USA), 2000.

[17] Konuk, I., Yu, S., \& Gracie, R., An ALE FEM Model of Ice Scour, Proceedings of the 11th International Conference of the International Association of Computer Methods and Advances in Geomechanics, Turin, Italy, Volume 3, pp. 63-70, 2005.

[18] Souli M., Ouahsine A., \& Lewin L., "Arbitrary Lagrangian Eulerian Formulation for Fluid-Structure Interaction Problems", Computer Methods in Applied Mechanics and Engineering, Volume 190, Pages 659$675,2000$. 
[19] LS-DYNA Theoretical Manual, Livermore Software Technology Corporation, compiled by John O. Hallquist, 1998.

[20] J.H. Prevost \& R. Popescu, Constitutive Relations for Soil Materials, Electronic Journal of Geotechnical Engineering, ASCE, 1996. http://www.ejge.com/1996/Ppr9609/Ppr9609.htm

[21] Sandler, I.S., DiMaggio, F.L., \& Baladi, G.Y., Generalized Cap Model for Geological Materials, Journal of Geotechnical Engineering Division, ASCE, 102, No. GT7, pp. 683-699, 1976.

[22] Sandler, I. S. \& Rubin D., An algorithm and a modular subroutine for the CAP model, International Journal for Numerical and Analytical Methods in Geomechanics, 3 (2), pp. 173 - 186, 1979.

[23] Sandler, I.S., DiMaggio, F.L., \& Baron, M.L., An Extension of the Cap Model - Inclusion of Pore Pressure Effects and Kinematic Hardening to Represent an Anisotropic Wet Clay, Chapter 28, Mechanics of Engineering Materials. Edited by C.S. Desai and R.H. Gallagher, John Wiley \& Sons Ltd., 1984.

[24] Simo, J.C., J.W. Ju, K.S. Pister, \& R.L. Taylor, Assessment of Cap Model: Consistent Return Algorithms and Rate-Dependent Extension, Journal of Engineering Mechanics, 114(2), pp. 191-218, 1988.

[25] Daddazio, R., Ettouney M., \& Sandler I, Nonlinear Dynamic Slope Stability Analysis, Journal of Geotechnical Engineering, 113(4), pp. 285-298, 1987.

\section{Appendix - soil properties and notation}

\begin{tabular}{|c|c|c|c|c|c|c|c|c|c|}
\hline \multicolumn{5}{|c|}{ NOTATION \& REMARKS } & \multicolumn{5}{|c|}{ CASES STUDIED IN THE PAPER } \\
\hline Parameter & $\begin{array}{c}\text { Notation in our } \\
\text { papers }\end{array}$ & $\begin{array}{c}\begin{array}{c}\text { Notation in } \\
\text { LS-DYNA } \\
\text { Manual }\end{array} \\
\end{array}$ & $\begin{array}{c}\text { Units } \\
\text { [British] }\end{array}$ & $\begin{array}{l}\text { Units } \\
\text { [SI] }\end{array}$ & Case1107G & Case1124G & Case1125G & Case1126G & Case1128G \\
\hline Density & $\rho$ & $\mathrm{RO}$ & & $\mathrm{kg} / \mathrm{m}^{\wedge} 3$ & 1600 & 1600 & 1600 & 1600 & 1600 \\
\hline Bulk Modulus & K & BULK & $\mathrm{ksi}$ & $\mathrm{Pa}$ & $1.00 \mathrm{E}+07$ & $1.00 \mathrm{E}+07$ & $1.00 \mathrm{E}+07$ & $1.00 \mathrm{E}+07$ & $1.00 \mathrm{E}+07$ \\
\hline \multirow[t]{8}{*}{ Shear Modulus } & $\mathrm{G}$ & $G$ & ksi & $\mathrm{Pa}$ & $9.60 \mathrm{E}+05$ & $9.60 \mathrm{E}+05$ & $9.60 \mathrm{E}+05$ & $9.60 \mathrm{E}+05$ & $9.60 \mathrm{E}+05$ \\
\hline & $\alpha$ & ALPHA & $\mathrm{ksi}$ & $\mathrm{Pa}$ & 500 & 500 & 500 & 500 & 500 \\
\hline & $\theta$ & THETA & & & 0.1 & 0.13 & 0.142 & 0.144 & 0.145 \\
\hline & $\gamma$ & GAMMA & ksi & $\mathrm{Pa}$ & 0 & 0 & 0 & 0 & 0 \\
\hline & $\beta$ & BETA & $k \sin ^{\wedge}(-1)$ & $\mathrm{Pa}^{\wedge}(-1)$ & 0 & 0 & 0 & 0 & 0 \\
\hline & $\mathrm{R}$ & $\mathrm{R}$ &  & & 4 & 4 & 4 & 4 & 4 \\
\hline & D & D & $k \operatorname{si}^{\wedge}(-1)$ & $\mathrm{Pa}^{\wedge}(-1)$ & $1.26 \mathrm{E}-06$ & $1.26 \mathrm{E}-06$ & $1.26 \mathrm{E}-06$ & $1.26 \mathrm{E}-06$ & $1.26 \mathrm{E}-06$ \\
\hline & W & W & & ... & 0.06 & 0.06 & 0.06 & 0.06 & 0.06 \\
\hline Initial CAP location & & $\mathrm{XO}$ & & & 0 & 0 & 0 & 0 & 0 \\
\hline Kinematic hardening & & C & & & & & & & \\
\hline Kinematic hardening & & $\mathrm{N}$ & & & & & & & \\
\hline \multirow[t]{2}{*}{ Tension Cut-off } & & TOFF & ksi & $\mathrm{Pa}$ & -5000 & -5000 & -5000 & -5000 & -5000 \\
\hline & & & ksi & & & & & & \\
\hline Poisson ratio & $\mathrm{v}$ & & 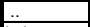 & & 0.45 & 0.45 & 0.45 & 0.45 & 0.45 \\
\hline Young's Modulus & $E$ & & ksi & $\mathrm{MPa}$ & 2790697.67 & 2790697.67 & 2790697.67 & 2790697.67 & 2790697.67 \\
\hline Cohesion & & & ksi & $\mathrm{Pa}$ & 410.41 & 408.47 & 408.25 & 408.25 & 408.25 \\
\hline Friction Angle & & &.. &.. & 13.83 & 17.67 & 19.18 & 19.43 & 19.55 \\
\hline
\end{tabular}

